\author{
활성탄의 기공구조에 따른 아세톤 증기와 \\ 톨루엔 증기의 흡착 및 탈착특성 비교 \\ 이송우 · 나영수 ${ }^{1}$ - 안창덕 ${ }^{1)} \cdot$ 이민규 ${ }^{*}$ \\ 부경대학교 화학공학과, ${ }^{1}$ 세계화학공업(주) 연구소 \\ (2012년 5월 21일 접수; 2012년 7월 26일 수정; 2012년 10월 5일 채택)
}

\title{
Comparison of Adsorption and Desorption Characteristics of Acetone Vapor and Toluene Vapor on Activated Carbons According to Pore Structure
}

\author{
Song-Woo Lee, Young-Soo $\mathrm{Na}^{1)}$, Chang-Doeuk $\mathrm{An}^{1)}$, Min-Gyu Lee \\ Department of Chemical Engineering, Pukyong National University, Busan 608-739, Korea \\ ${ }^{1)}$ Segye Chem. Co., Ltd., $R$ \& D Center, Kyungnam 626-120, Korea \\ (Manuscript received 21 May, 2012; revised 26 July, 2012; accepted 5 October, 2012)
}

\begin{abstract}
The purpose of this work is to study the adsorption and desorption characteristics of acetone vapor and toluene vapor from adsorption tower in the VOCs recovery device. The six kinds of activated carbon with different pore structures were used and the adsorption and desorption characteristics were compared according to pore structure, desorption temperature, and adsorption method, respectively. Adsorption capacity of acetone vapor and toluene vapor by batch method was higher than that by dynamic method. Especially, activated carbon with medium-sized or large pores had more difference in adsorption capacity according to adsorption methods as a result of gradually condensation of vapors on relatively mesopore and large pores. Activated carbons with relatively large pores and relatively small saturated adsorption capacity had excellent desorption ability.
\end{abstract}

Key Words : Activated carbon, Adsorption, Desorption, Acetone vapor, Toluene vapor, Pore structure

\section{1. 서 론}

여러 산업분야에서 광범위하게 사용되고 있는 휘 발성 유기화합물(volatile organic compounds, VOCs) 은 대부분이 건조공정에서 휘발되어 대기 중으로 배 출되고 있다. 이렇게 배출된 $\mathrm{VOCs}$ 는 산업현장의 작

${ }^{*}$ Corresponding author : Min-Gyu Lee, Department of Chemical Engineering, Pukyong National University, Busan 608-739, Korea

Phone: +82-51-629-6435

E-mail: mglee@pknu.ac.kr
업환경을 오염시킬 뿐만 아니라 화재, 폭발 등의 사고 와 인체장애의 심각한 원인이 되고 있어 작업장에서 기상으로 배출되는 VOCs를 제거하기 위한 많은 연구 가 수행되고 있다(Khan과 Ghoshal, 2000). 지금까지 $\mathrm{VOCs}$ 를 제거하기 위한 연구에서 흡착법이 가장 효과 적인 방법으로 알려져 있으며, 흡착에 관한 연구는 활 성탄을 흡착제로 주로 사용하고 흡착제의 종류에 따 른 흡착량을 평가하거나 온도변화에 따른 흡착능을 비교 고찰한 것이 대부분을 차지하고 있다. 최근의 연 구는 활성탄의 표면 및 내부에 형성된 기공별 표면적 
과 흡착량, 활성탄 기공별 기공부피와 흡착량, 그리고 이 값들 사이의 상관관계를 고찰하였으며, 또한 활성 탄 특정 기공영역에서의 흡착능과 흡착질의 분자크 기, 또는 흡착질 극성과의 상관관계를 고찰하였다 ( $\operatorname{Lim}$ 등, 2005; Lee 등, 2006; Lee 등, 2005a, 2007, 2008a). 그리고 제올라이트나 실리카-알루미나와 같 은 무기계 흡착제의 흡착특성을 고찰하였다(Ahn 등, 1999; Lee 등, 1999a; Lee 등, 2005b, 2008b, 2011a, 2011b). 이에 반해 여러 성분으로 구성된 다성분계 증 기의 흡착(Kim 등, 2007; Lee 등, 2007)과 회수를 위 한 다양한 연구는 아직 미미하며, 흡착능 향상을 위해 여러종류의 활성탄을 복합적으로 사용하거나 다중 흡 착층의 충전방법에 따른 흡착특성을 고찰한 연구는 많지 않은 실정이다(Lee 등, 2012). 흡착제를 사용한 연구의 대부분이 흡착에 관련된 연구이고 탈착 및 재 생과 회수에 관련된 연구는 아직 부족한 실정이다 (Torrents 등, 1997; San Miguel 등, 2001; Popescu 등, 2003). 흡착법을 이용한 용매회수에서 가장 중요한 단 계는 탈착이며, 이것은 흡착제의 재생단계이다. 일반 적으로 탈착은 흡열공정이므로 에너지가 공급되어야 하는 문제점이 있다. 그러므로 탈착에 의한 용제회수 는 요구되는 에너지를 고려하여 최적의 탈착조건을 찾아야 경제적인 회수가 가능하다(Lee 등, 1999b).

본 연구는 VOCs 회수용 장치에서 흡착탑에 흡착 된 acetone과 toluene의 효과적인 탈착을 위한 탈착특 성을 고찰한 것이다. 내부의 기공구조가 다른 6종류의 활성탄을 acetone과 toluene 증기로 흡착시킨 후 탈착 시키며 활성탄의 기공구조, 탈착온도, 탈착공기의 유 량 변화에 따른 탈착특성을 비교 고찰하였다.

\section{2. 재료 및 방법}

\section{1. 재료}

흡착제는 6 종류의 상업화된 성형 활성탄을 사용하 였다. 6 종류의 활성탄은 미국의 Calgon, 미국의 Norit, 일본의 Takeda, 미국의 Westvaco, 그리고 독일 Donau Carbon에서 입수한 활성탄이며, 입자크기는 0.86 $1.4 \mathrm{~mm}$ 로 일정하게 조절하여 사용 전에 충분히 건조 시켜 활성탄 내부에 있을 수 있는 분술물을 제거하여 사용하였다. 이 6 종류의 활성탄은 Table 1 과 같이 각 각 $\mathrm{CCA}, \mathrm{CCG}, \mathrm{CNO}, \mathrm{CTA}, \mathrm{CWE}$, 그리고 $\mathrm{CGE}$ 로 명 명하였다. 흡착질은 $\mathrm{VOCs}$ 물질 중 대표적인 용매인 acetone과 toluene을 사용하였다. Acetone은 Fischer Scientific의 순도 $99.9 \%$ 를 사용하였고, toluene은 Junsei의 순도 $99.9 \%$ 를 사용하였다.

\section{2. 장치 및 방법}

탈착용 시료는 acetone 증기와 toluene 증기를 활성탄 에 포화흡착시켜 사용하였으며, 회분식(batch method) 과 연속식(dynamic method)으로 포화시킨 후 포화방 법에 따른 포화흡착량의 차이를 비교하였다. 회분식 흡착은 활성탄 $5 \mathrm{~g}$ 을 스텐 그물망 속에 넣고 acetone 증기 및 toluene 증기로 각각 포화된 밀폐된 유리용기 속 에서 활성탄의 무게 변화가 없을 때까지 방치하며 충분 히 포화흡착시켰고, 연속식 흡착은 전보(Lee 등, 2005a) 에서 사용한 연속식 흡착장치를 사용한 방법으로 포화 흡착시켜으며 이것을 탈착용 시료로 사용하였다.

탈착은 Fig. 1과 같은 탈착장치를 사용하였다. 펌프 를 통해 공급되는 탈착공기는 실리카겔이 충진된 건 조병(drying bottle)을 통과하며 공기에 포함된 수분이

Table 1. Characteristics of activated carbons

\begin{tabular}{cccccccc}
\hline \multirow{2}{*}{ Sample } & \multirow{2}{*}{ Raw material } & Maker & $\begin{array}{c}\mathrm{S}_{\text {BET }} \\
\mathrm{m}^{2} / \mathrm{g}\end{array}$ & $\begin{array}{c}\mathrm{V}_{\text {BJH }} \\
\mathrm{cm}^{3} / \mathrm{g}\end{array}$ & $\begin{array}{c}\mathrm{V}_{\mathrm{T}} \\
\mathrm{cm}^{3} / \mathrm{g}\end{array}$ & $\begin{array}{c}\mathrm{D}_{\mathrm{p}} \\
\AA\end{array}$ \\
\hline \hline 1 & CCA & Coal & U.S.A., Calgon (WS465) & 1,017 & 0.410 & 0.481 & 19.12 \\
\hline 2 & CCG & Coconut shell & U.S.A., Calgon (WSC470) & 1,242 & 0.518 & 0.613 & 19.75 \\
\hline 3 & CNO & Coal & U.S.A. Norit Americas (RB4) & 1,199 & 0.433 & 0.599 & 19.98 \\
\hline 4 & CTA & Wood & Japan, Takeda & 1,288 & 0.473 & 0.607 & 18.8 \\
\hline 5 & CWE & Wood & U.S.A., Westvaco & 1.260 & 0.870 & 0.967 & 31.0 \\
\hline 6 & CGE & Wood & German, Donau Carbon & 1,342 & 0.720 & 0.808 & 24.1 \\
\hline
\end{tabular}


제거되었고 공기의 유량은 부착된 유량계로 조절하였 다. 탈착장치의 탈착온도를 정확히 조절하기 위해 유 입공기는 탈착관에 유입되기 전에 히터에 의해 80 $90^{\circ} \mathrm{C}$ 로 가열시켰다. 탈착관에 유입된 공기는 탈착관 내의 시료를 통과하며 흡착질을 탈착하여 외부로 배 출되었으며, 탈착관 내의 온도는 전기로로 일정하게 조절하였다. 탈착량은 digital balance를 이용하여 탈 착 전후 시료의 무게를 측정하여 계산하였다. Acetone 및 toluene으로 포화된 활성탄의 초기 무게를 측정하 고, 탈착실험 시작 후 일정 시간이 경과 할 때마다 무 게를 측정하여 그 무게 감소로 탈착량을 계산했다.

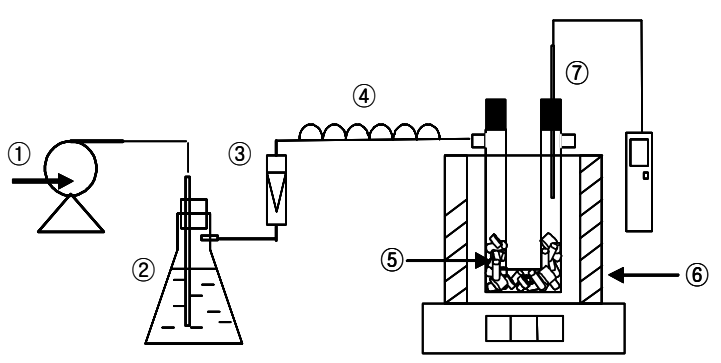

Fig. 1. Schematic diagrmam of apparatus for desorption system (1) air pump, (2) dry bottle, (3) flow meter, (4) heater, (5) activated carbon, (6) electric oven, (7) thermocouple).

\section{3. 분석}

활성탄의 비표면적( $\mathrm{S}_{\mathrm{BET}}$, specific surface area), 누 적기공부피( $\mathrm{V}_{\mathrm{BJH}}$, cumulative pore volume), 그리고 총기공부피( $\mathrm{V}_{\mathrm{T}}$, total pore volume)는 $\mathrm{BET}$ 비표면측 정기(Micromeritics, ASAP-2010)를 이용하여 측정하 였다. $\mathrm{BET}$ 측정 전 시료는 온도 $250^{\circ} \mathrm{C}$ 에서 완전히 탈 기시킨 후 사용하였으며, 총기공부피는 포화압력에서 흡착된 총 질소의 부피로부터 계산하였고, 누적세공 부피는 BJH(Barrett, Joyner and Halendar) method로 계산하였으며, 전체표면적 중 external surface와 micro surface가 차지하는 비율은 t-Plot 방법으로 계 산하였다(Micromeritics, 1997).

\section{3. 결과 및 고찰}

\section{1. 활성탄 종류별 기공구조의 비교}

$\mathrm{BET}$ 측정기를 사용하여 측정한 6종류 활성탄의 비
표면적 $\left(\mathrm{S}_{\mathrm{BET}}\right)$, 누적기공부피 $\left(\mathrm{V}_{\mathrm{BJH}}\right)$, 총기공부피 $\left(\mathrm{V}_{\mathrm{T}}\right)$, 그리고 평균기공크기 $\left(\mathrm{D}_{\mathrm{p}}\right)$ 의 기공구조를 활성탄 종류 별로 Table 1에 나타내었다.

사용한 활성탄의 $\mathrm{BET}$ 비표면적 $\left(\mathrm{S}_{\mathrm{BET}}\right)$ 은 약 1,000 $\sim 1,340 \mathrm{~m}^{2} / \mathrm{g}$ 범위의 비표면적 값을 가지고 있었으며, $\mathrm{CGE}$ 와 CTA 활성탄이 비교적 높은 비표면적 값을 가 지고 있었고 $\mathrm{CCA}$ 활성탄이 비교적 낮은 비표면적 값 을 가지고 있었다. 그리고 누적기공부피 $\left(\mathrm{V}_{\mathrm{BJH}}\right)$ 와 총기 공부피 $\left(\mathrm{V}_{\mathrm{T}}\right)$ 는 $\mathrm{CWE}$ 와 $\mathrm{CGE}$ 활성탄이 비교적 높은 기 공부피 값을 가지고 있었고, $\mathrm{CCA}$ 활성탄이 가장 낮은 기공부피 값을 가지고 있었으며, 비교한 활성탄은 최 대 2 배의 기공부피 값 차이를 가지고 있었다. 이것은 $\mathrm{CGE}$ 와 $\mathrm{CWE}$ 활성탄의 평균기공크기 $\left(\mathrm{D}_{\mathrm{p}}\right)$ 가 각각 $24.1 \AA$ 및 $31 \AA$ 으로 비교한 다른 활성탄에 비해 최대 1.6 배 까지 평균지름이 큰 기공으로 형성되어 있기 때 문으로 판단되었다. $\mathrm{BJH}$ 방법으로 측정한 누적세공 부피 $\left(\mathrm{V}_{\mathrm{BJH}}\right)$ 를 세공직경 $10 \AA$ 이하, $11 \sim 20 \AA, 21 \sim$ $30 \AA$, $31 \sim 500 \AA$, 그리고 $500 \AA$ 이상으로 세공부피 를 세분하여 Fig. 2 에 나타내었고, 활성탄의 전체표면 적 중 external surface와 micro surface가 차지하는 비 율은 Fig. 3에 각각 비교하여 나타내었다. 비교한 활성 탄 중에서 직경이 $10 \AA$ 이하의 세공을 $\mathrm{CCG}$ 와 CTA 활성탄이 가장 많이 가지고 있었고, $10 \AA$ 이상의 세 공은 $\mathrm{CWE}$ 와 $\mathrm{CGE}$ 활성탄에서 비교적 많이 발달한 것을 볼 수 있었다. 특히 $\mathrm{CWE}$ 활성탄은 세공직경 30 $\sim 500 \AA$ 범위의 부피가 가장 많이 발달해 있었다. 그

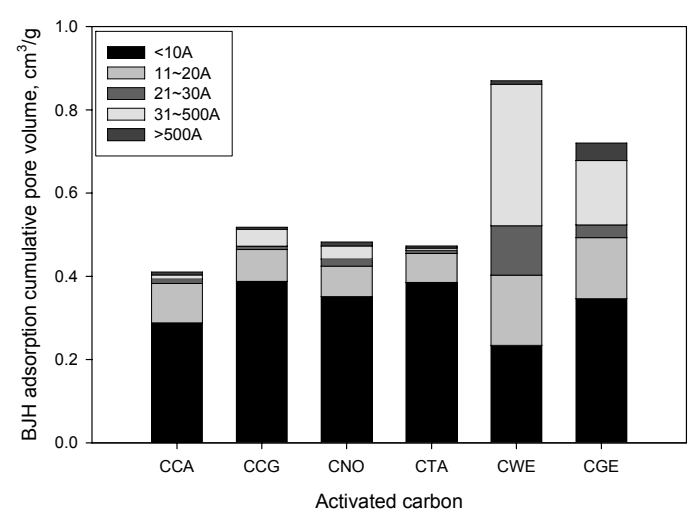

Fig. 2. Comparison of cumulative pore volume of various activated carbons according to pore size calculated by BJH method. 


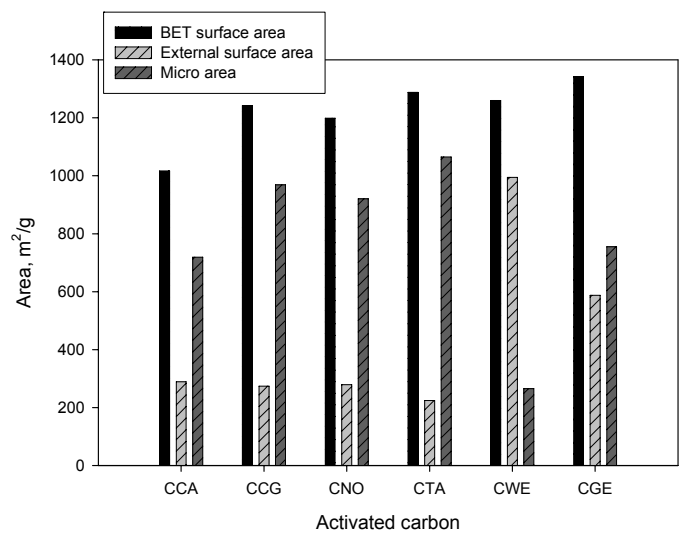

Fig. 3. Comparison of external surface areas and micro areas of various activated carbons calculated by t-plot method.

리고 CWE와 CGE 흡착제는 전체면적에서 external surface area가 비교적 많이 발달해 있었으며, 나머지 흡 착제들은 micro area가 많이 차지하고 있었다. External surface area가 큰 것은 중간이상의 세공이 많이 발달 한 결과이다. Fig. 2 의 결과와 같이 중간이상의 세공이 많이 발달한 흡착제가 external surface area가 큰 것을 확인 할 수 있었다.

\section{2. 흡착방법에 따른 활성탄 종류별 acetone과 toluene의 흡착특성 비교}

기공구조가 다른 6종류의 활성탄에 대해 흡착방법 에 따른 acetone 증기와 toluene 증기의 포화흡착량 차 이를 고찰하기 위해 연속식과 회분식 흡착방법으로 흡착시켜 측정한 포화흡착량을 비교하였다. 연속식은 흡착온도 $25^{\circ} \mathrm{C}$ 에서 증기의 유입농도를 $5,000 \mathrm{ppmv}$ 로 조절하고 증기의 유속을 $0.5 \mathrm{~L} / \mathrm{min}$ 로 설정하여 파과 실험을 수행하여 포화흡착량을 계산하였다.

활성탄 종류별 acetone의 포화흡착량은 Fig. 4에, 활성탄 종류별 toluene의 포화흡착량은 Fig. 5 에 각각 나타내었다. 비교 결과 연속식 보다 회분식의 흡착량 이 많았으며, 특히 중간 크기이상의 기공이 많은 흡착 제인 CWE와 CGE 흡착제에서 흡착방법에 따른 포화 흡착량의 차이가 많았다. 그리고 흡착 경과시간에 따 른 차이도 있는 것으로 나타났다. 흡착제를 포화시키 는데 걸리는 시간은 연속식이 5 7시간, 회분식은 3
일 이상으로 연속식 보다 회분식이 훨씬 길었으며, 회 분식에서는 중간기공 이상의 큰 기공에 흡착질이 서 서히 응축되며 나타난 결과로 사료되었다.

회분식에서는 흡착시간 경과에 따른 흡착량의 차 이가 많았기 때문에 acetone의 포화흡착량을 경과시 간을 4 일과 15 일로 구분해서 연속식과 비교하여 Fig. 4에 나타내었다. 경과시간에 따른 acetone의 흡착량 차이는 매우 많았다. 특히 미세세공이 많이 발달하여 표면적이 큰 흡착제에서 흡착시간의 경과에 따른 흡 착량 차이가 큰 것을 알 수 있었다. Acetone은 흡착방 법에 따른 포화흡착량의 차이가 비교한 활성탄 전체 에서 비교적 크게 나타났지만 toluene은 흡착방법에 따른 포화흡착량의 차이가 기공부피가 큰 $\mathrm{CWE}, \mathrm{CGE}$ 활성탄을 제외하고는 크지 않았다. Acetone은 분자크 기가 $4.3 \AA$ 정도(Lee 등, 2005a)로 미세한 기공까지 확산 할 수 있기 때문에 흡착시간이 경과 할수록 활성 탄 내부에 흡착 응축하는 것으로 사료되며, toluene은 분자크기가 $7 \AA$ 정도(Lee 등, 2006)로 acetone에 비해 미세한 기공까지 확산하지 못하고 상대적으로 큰 기 공에 확산하기 때문에 Fig. 2의 세공구조 비교에서 10 $\AA$ 이상의 기공이 많이 발달한 $\mathrm{CWE}, \mathrm{CGE}$ 활성탄에 서 포화흡착량의 차이가 큰 것으로 사료되었다.

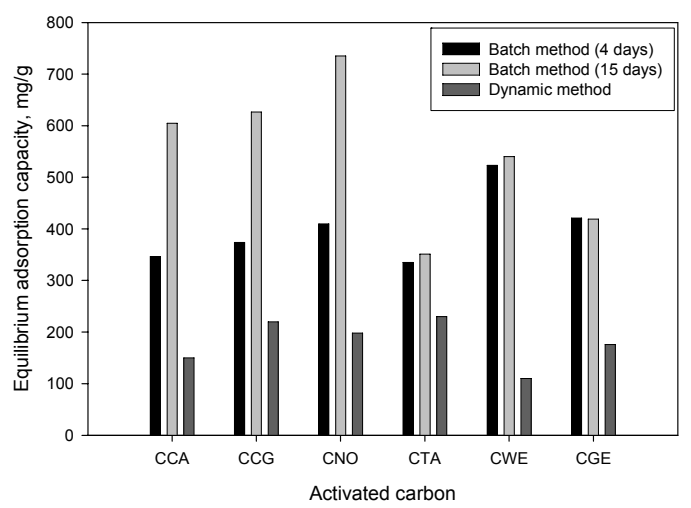

Fig. 4. Comparison of the equilibrium adsorption capacities of acetone vapor adsorbed on various activated carbons according to adsorption method at $25^{\circ} \mathrm{C}$ (dynamic method: bed capacity, $5 \mathrm{~g}$; acetone vapor concentration, 5,000 ppmv; flow rate, $0.5 \mathrm{~L} / \mathrm{min}$ ). 


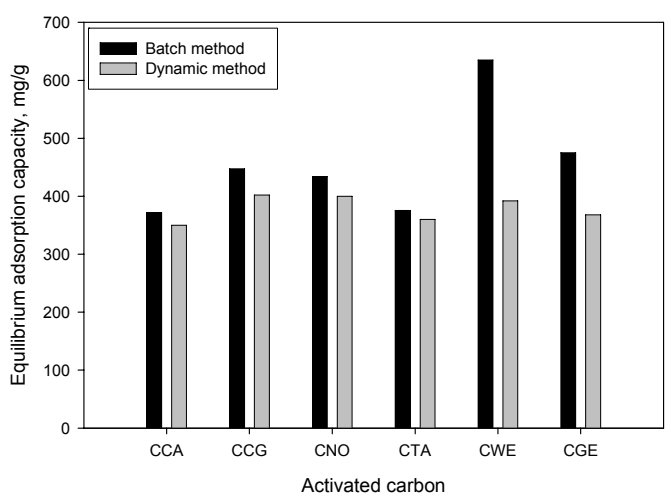

Fig. 5. Comparison of the equilibrium adsorption capacities of toluene vapor adsorbed on various activated carbons according to adsorption method at $25^{\circ} \mathrm{C}$ (dynamic method: bed capacity, $5 \mathrm{~g}$; toluene vapor concentration, 5,000 ppmv; flow rate, $0.5 \mathrm{~L} / \mathrm{min}$ ).

\section{3. 활성탄 종류에 따른 acetone과 toluene의 탈착특성 비교}

먼저 toluene의 효과적인 탈착온도를 설정하기위해 온도 $120^{\circ} \mathrm{C}$ 와 $150^{\circ} \mathrm{C}$ 에서 toluene으로 포화된 $\mathrm{CCA}$ 활 성탄과 $\mathrm{CNO}$ 활성탄을 이용하여 탈착 실험한 결과를 Fig. 6에 나타내었다. 온도 $120^{\circ} \mathrm{C}$ 에서 $\mathrm{CNO}$ 활성탄의 경우는 흡착된 toluene의 양이 $20 \mathrm{wt} \%$ 이하로는 탈착 되지 않았기 때문에 온도를 $150^{\circ} \mathrm{C}$ 로 상승시킨 결과 $13 \mathrm{wt} \%$ 까지 탈착되었으며, $\mathrm{CCA}$ 활성탄은 온도 $120^{\circ} \mathrm{C}$ 에서 $13 \mathrm{wt} \%$ 이하로는 탈착되지 않아, 온도를 $150^{\circ} \mathrm{C}$ 로 상승시킨 결과 $9 \mathrm{wt} \%$ 까지 탈착시킬 수 있었다. 이

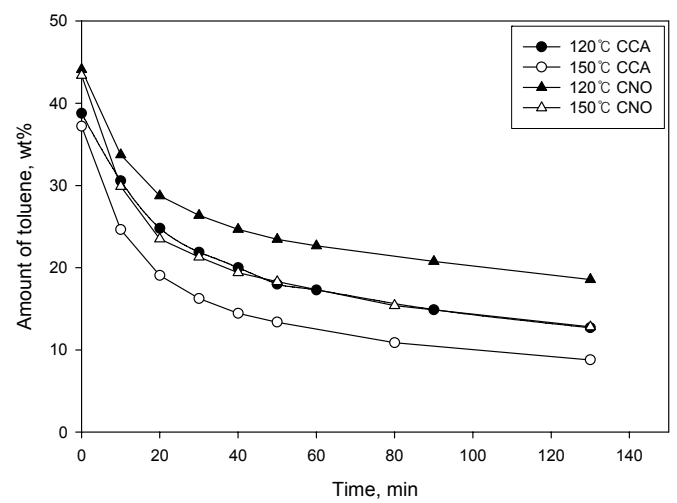

Fig. 6. Comparison of desorption of toluene on activated carbons at $120^{\circ} \mathrm{C}$ and $150^{\circ} \mathrm{C}$ with air flow rate of 0.1 $\mathrm{L} / \min$ (bed capacity, $5 \mathrm{~g}$ ).
것은 $\mathrm{CNO}$ 활성탄이 $\mathrm{CCA}$ 활성탄에 비해 $10 \AA$ 이하의 미세세공이 많아 이 좁은 세공들이 탈착에 저항으로 작용하여 탈착이 잘 되지 않는 것으로 판단되었다.

따라서 toluene 탈착온도는 $150^{\circ} \mathrm{C}$ 를 적합한 온도로 고려할 경우, 이 온도에서 toluene의 증기압은 2,100 $\mathrm{mmHg}$ 이고 이 증기압은 $87^{\circ} \mathrm{C}$ 에서의 acetone의 증기 압과 같은 값이다. 그리하여 acetone의 증기압이 $2,100 \mathrm{mmHg}$ 인 $87^{\circ} \mathrm{C}$ 및 $80^{\circ} \mathrm{C}$ 에서 $\mathrm{CNO}$ 활성탄으로 acetone의 탈착 실험을 행하여 동일한 증기압을 갖는 $150^{\circ} \mathrm{C}$ 에서 행한 toluene 탈착실험 결과를 Fig. 7에 비 교하여 나타내었다. $87^{\circ} \mathrm{C}$ 보다 $80^{\circ} \mathrm{C}$ 의 결과가 $150^{\circ} \mathrm{C}$ 의 toluene 탈착결과와 더 비슷한 조건으로 판단되어 온 도 $80^{\circ} \mathrm{C}, 0.1 \mathrm{~L} / \mathrm{min}$ 의 조건으로 각 활성탄의 acetone 탈착결과를 비교하였다.

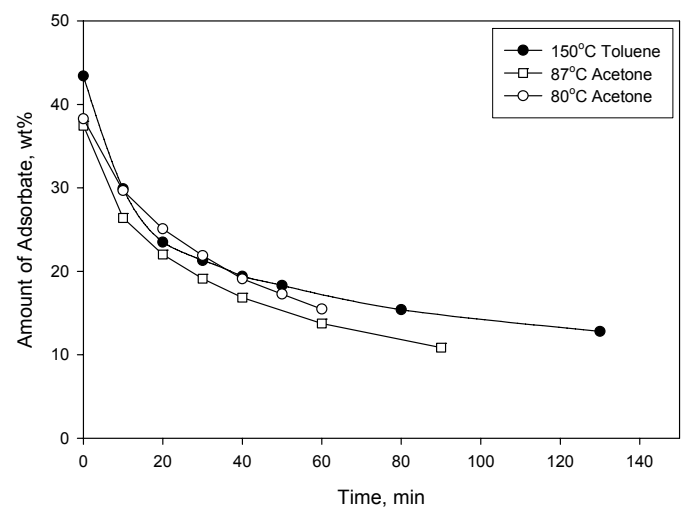

Fig. 7. Comparison of desorption of toluene and acetone on $\mathrm{CNO}$ activated carbon with air flow rate of 0.1 $\mathrm{L} / \mathrm{min}$ (bed capacity, $5 \mathrm{~g}$ ).

Fig. 8 과 Fig. 9는 toluene과 acetone이 서로 같은 증 기압 $(2,100 \mathrm{mmHg})$ 을 갖는 조건에서 각 활성탄들의 탈착 특성을 나타낸 것이다. Fig. 8은 활성탄 종류에 따른 acetone의 탈착특성을 비교한 것으로 탈착온도 $80^{\circ} \mathrm{C}$, 탈착공기 유량 $0.1 \mathrm{~L} / \mathrm{min}$, 활성탄 $5 \mathrm{~g}$ 의 실험조 건으로 탈착시켜 비교한 결과이다. 탈착능이 가장 좋 은 것은 $\mathrm{CWE}$ 였고, 그 다음이 $\mathrm{CGE}, \mathrm{CCG}$ 이었으며, $\mathrm{CNO}, \mathrm{CTA}$, 그리고 $\mathrm{CCG}$ 활성탄의 탈착능이 제일 떨 어졌다. 이 결과는 toluene의 결과와 거의 일치한 결과 였으며 세공크기별로 부피를 비교한 Fig. 2 의 결과와 거의 일치함을 알 수 있었다. 내부에 상대적으로 큰 세 
공들 많고 $10 \AA$ 이하의 세공이 적은 흡착제의 탈착능 이 우수하였다. Fig. 9는 활성탄 종류에 따른 toluene 의 탈착특성을 비교한 것으로 탈착온도 $150^{\circ} \mathrm{C}$, 탈착 공기 유량 $0.1 \mathrm{~L} / \mathrm{min}$, 활성탄 $5 \mathrm{~g}$ 의 실험조건으로 탈 착시켜 비교한 결과이다.

$\mathrm{CNO}$ 와 $\mathrm{CCA}$ 활성탄 탈착실험결과 온도 $150^{\circ} \mathrm{C}$, 공 기유량 $0.1 \mathrm{~L} / \mathrm{min}$ 조건이 가장 적합하다고 판단되어 다른 활성탄들을 온도 $150^{\circ} \mathrm{C}$ 의 같은 조건으로 탈착시 켜 비교한 결과는 Fig. 9 와 같다. 탈착능이 가장 좋은 것이 $\mathrm{CWE}$ 였고, 그 다음이 $\mathrm{CGE}, \mathrm{CCA}$ 이었으며, $\mathrm{CNO}, \mathrm{CTA}$, 그리고 $\mathrm{CCG}$ 활성탄의 탈착능이 제일 떨 어졌다. 탈착능이 좋은 흡착제는 흡착제 내부에 상대

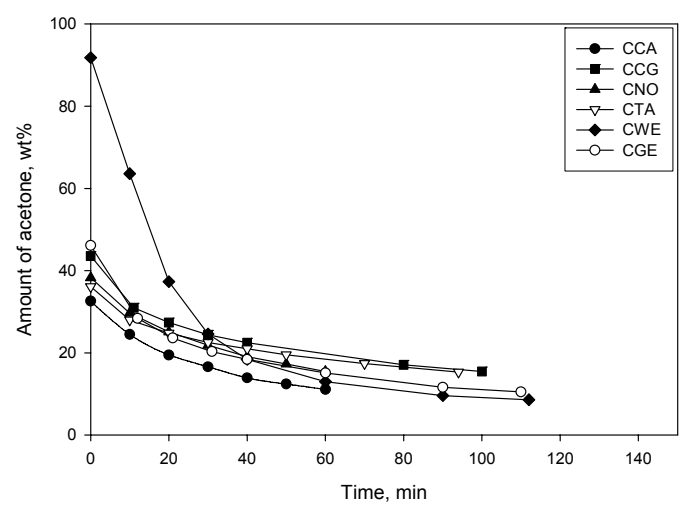

Fig. 8. Comparison of desorption of acetone on activated carbon at $80^{\circ} \mathrm{C}$ with air flow rate of $0.1 \mathrm{~L} / \mathrm{min}$ (bed capacity, $5 \mathrm{~g}$ ).

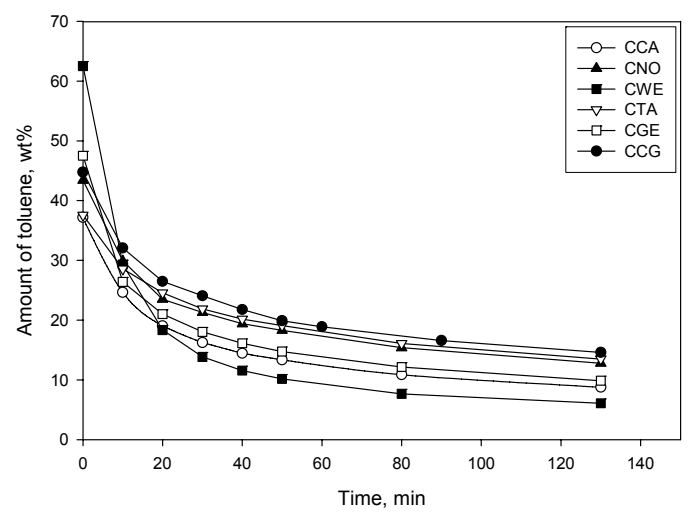

Fig. 9. Comparison of desorption of toluene on various adsorbents at $150^{\circ} \mathrm{C}$ with air flow rate of $0.1 \mathrm{~L} / \mathrm{min}$ (bed capacity, $5 \mathrm{~g}$ ).
적으로 큰 세공들 많은 흡착제였고, 상대적으로 포 화흡착량이 적은 흡착제의 탈착능이 컸다. 특히 10 $\AA$ 이하의 세공부피가 많이 발달한 활성탄의 탈착능 이 상대적으로 작다는 것을 알 수 있었다. 탈착실험 한 각 흡착제의 세공크기별 부피를 탈착능에 따라 비교한 Fig. 2 의 결과에서도 $10 \AA$ 이상의 세공부피 가 많이 발달한 흡착제의 탈착능이 큰 것을 확인 할 수 있었다.

\section{4. 결 론}

흡착방법에 따른 비교에서 연속식 보다 회분식의 흡착량이 많았으며, 특히 중간 크기이상의 기공이 많 은 흡착제인 CWE와 CGE 흡착제에서 흡착방법에 따 른 포화흡착량의 차이가 많았다. 회분식에서는 중간 세공 이상의 큰 기공에 흡착질이 서서히 응축되며 나 타난 결과로 사료되었다.

경과시간에 따른 비교에서 acetone의 포화흡착량 차이는 매우 많았다. 특히 미세세공이 많이 발달하여 표면적이 큰 흡착제에서 흡착시간의 경과에 따른 흡 착량 차이가 큰 것을 알 수 있었다. Acetone은 분자크 기가 toluene에 비해 상대적으로 작아 미세한 기공까 지 확산할 수 있기 때문에 흡착시간이 경과 할수록 활 성탄 내부에 흡착 응축하여 포화흡착량의 차이가 큰 것으로 사료되었다.

탈착특성 비교에서 acetone의 탈착특성은 내부에 상대적으로 큰 세공들 많고 $10 \AA \AA$ 이하의 세공이 적은 흡착제의 탈착능이 우수하였다. toluene의 탈착특성 은 활성탄 내부에 상대적으로 큰 세공들 많고 상대 적으로 포화흡착량이 적은 활성탄의 탈착능이 우수 하였다. 특히 $10 \AA$ 이하의 세공부피가 많이 발달한 활성탄의 탈착능이 상대적으로 작다는 것을 알 수 있었다.

\section{감사의 글}

본 논문은 기본적인 연구를 수행하는데 도움을 받 은 환경부 차세대핵심환경기술개발사업(과제번호 : 012-061-046)과 이를 바탕으로 응용 수행된 지식경제 부 기술혁신사업 중 자원순환 및 산업에너지기술개발 
보급사업(과제번호 : 20105020200020)의 지원에 의 하여 연구되었으며 이에 감사드립니다.

\section{참 고 문 헌}

Ahn, H. W., Park, J. S., Koo, K. K., Lee, C. H., 1999, Sorption kinetics of $\mathrm{N}_{2}$ on pelletized zeolite $4 \mathrm{~A}$ and 5A (in Korean), HWAHAK KONGHAK, 37(3), 364-372.

Khan, F. I., Ghoshal, A. K., 2000, Removal of volatile organic compound from polluted air, Journal of Loss Prevention in the Process Industries, 13, 527-545.

Kim, H. W., Lee, S. W., Lee, M. G., Cheon, J. K., 2007, Variations of equilibrium adsorption capacities according to type and mixing fraction of binary mixed gas on activated carbon fixed-bed (in korean), J. Environ. Sci., 16(10), 1197- 1202.

Lee, H. J., Lee, H. K., Park, G. I., Ro, S. G., Choi, H. S., Lee, Y. T., 1999a, Adsorption property of water vapor on the modified natural zeolite (in Korean), J. Korean Soc. Environ. Engrs., 21(4), 643-651.

Lee, H. U., Na, K. S., Moon, I., Song, H. K., Na, B. K., 1999b, Revery of MEK with polymer adsorbent (in Korean), HWAHAK KONGHAK, 37(2), 276-283.

Lee, M. G., Lee, S. W., Kam, S. K., Lee, S. H., 2012, Variation of adsorption characteristics of binary vapor according to packing system of double-layer adsorption bed (in Korean), J. Environ. Sci., 21(3), 305-312.

Lee, M. G., Lee, S. W., Lee, S. H., 2006, Comparison of vapor adsorption characteristics of acetone and toluene based on polarity in activated carbon fixed-bed reactor, Korean J. Chem. Eng., 23(5), 773-778.

Lee, S. W., Bae, S. K, Kwon, J. H., Na, Y. S., An, C. D., Yoon, Y. S., Song, S. K., 2005a, Correlations between pore structure of activated carbon and adsorption characteristics of acetone vapor (in Korean), J. Korean Soc. Environ. Engrs., 27(6), 620-625.

Lee, S. W., Bae, S. K, Kwon, J. H., Na, Y. S., An, C. D., Yoon, Y. S., Song, S. K., 2005b, Adsorption characteristics of toluene vapor according to pore structure of zeolite 5A modified with hydrochloric acid (in Korean), J. Korean Soc. Environ. Engrs., 27(8), 807-812.
Lee, S. W., Cheon, J. K., Park, H. J., Lee, M. G., 2008a, Adsorption characteristics of binary vapors among acetone, MEK, benzene, and toluene, Korean J. Chem. Eng., 25(5), 1154-1159.

Lee, S. W., Kam, S. K., Lee, M. G., 2007, Comparison of breakthrough characteristics for binary vapors composed of acetone and toluene based on adsorption intensity in activated carbon fixed-bed reactor, J. Ind. Eng. Chem., 13(6), 911-916.

Lee, S. W., Kwon, J. H., Kang, J. H., Na, Y. S., An, C. D., Yoon, Y. S., Song, S. K., 2006, Adsorption characteristics of toluene vapor according to pore size distribution of activated carbon (in Korean), J. Environ. Sci., 15(7), 695-699.

Lee, S. W., Park, H. J., Lee, S. H., Lee, M. G., 2008b, Comparison of adsorption characteristics according to polarity difference of acetone vapor and toluene vapor on silica-aluminar fixed-bed reactor, J. Ind. Eng. Chem., 13, 10-17.

Lee, S. W., Na, Y. S., An, C. D., Lee, M. G., 2011a, Comparison of adsorption characteristics on zeolite 13X and silica-aluminar (in Korean), J. Environ. Sci., 20(6), 729-736.

Lee, S. W., Na, Y. S., An, C. D., Lee, M. G., 2011b, Adsorption Characteristics of water vapor on zeolite (in Korean), J. Environ. Sci., 20(5), 667-672.

Lim, J. K., Lee, S. W., Kam, S. K., Lee, D. W., Lee, M. G., 2005, Adsorption characteristics of toluene vapor in fixed-bed activated carbon column (in Korean), J. Environ. Sci., 14(1), 61-69.

Micromeritics, 1997, ASAP 2010 Manual.

Popescu, S., Joly, J. P., Carre, J., Danatoiu, C., 2003, Dynamic adsorption and temperature-programed desorption of VOCs (toluene, butyl acetate and butanol) on activated carbons, Carbon, 41, 739-748.

San Miguel, G., Lambert, S. D., Graham, J. D., 2001, The regeneration of field-spent granular-activated carbon, Wat. Res., 35(11), 2740-2748.

Torrents, A., Damera, R., Hao, O. J., 1997, Low-temperature thermal desorption of aromatic compounds from activated carbon, Journal of Hazardous Materials, 54, 141-153. 
